Accelerator Department

BROOKHAVEN NATIONAL LABORATORY

Associated Universities, Inc.

Upton, New York

AGS DIVISION TECHNICAI NOTE

№. 99

R.R. Adams, J.G. Cottingham, D.A. Davis and R.B. Gottschalk

September 29, 1972

\title{
SIEMENS POWER SUPPLY MOTOR-GENERATOR SET MOTOR ROTOR FAILURE
}

\section{Introduction}

The Siemens power supply is used to power the $33 \mathrm{GeV}$ Alternating Gradient Synchrotron main magnet. It consists of a motor-generator set (Fig. 1) supplying energy to banks of mercury-arc rectifiers through transformers. The motor is a wound-rotor induction motor rated at nine megawatts, 13800 volts, 3 phase, 60 hertz, $1200 \mathrm{rpm}$. The generator is rated at 50 MVA continuous 95 MVA surge, 7500 volts, 3 phase. The power supply output is 12000 volts, 7000 amperes, pulsed duty.

\section{Incidence of Fault}

Saturday, August 19, 1972, the Siemens motor-generator set motor rotor faulted. The following sequence of events took place.

At 1430, the Main Control Room requested that pulsing be stopped and generator excitation be disconnected. Approximately twenty seconds later, the motor breaker dropped out and the motor brake was energized automatically. The operator on duty heard a loud noise and saw flashing at the motor slip rings immediately after the motor dynamic brake went on. The operator opened the motor brake breaker manually via the control switch at the control console. In a few seconds, the motor dynamic brake went on for the second time automatically, accompanied again by a loud noise and flashing at the motor slip rings. The operator immediately opened the motor brake breaker manually. In a few more seconds the motor brake went on again automatically for the third time. With the help of the second operator, the motor brake was dis- 
connected manually and held off, the generator brake was energized and the motor-generator set was brought to a stop.

The Main Control Room was informed of the fault and the operator called in key engineering personnel to examine the consequences of the fault. Siemens Corp., Iselin, New Jersey, Mr. Max Detarding was informed by telephone.

\section{Fault Inspection}

After removing the slip-ring cover and the motor end shields, it was found that one or two rotor winding end connections and the rotor to slip-ring connections were severely burned. Figures 2 to 6 show different views of the external damage at the rotor winding end connections, and Figs. 7 to 9 show the physical damage at the rotor to slip-ring connections.

The motor rotor is wave wound (see Siemens drawing number TRA-W 1827/1 and OD3.1471-163417) with lower and upper slot half coils: The end connections are enclosed in a close fitting open-ended copper box and the space between the copper bars is filled with an added copper block. Siemens drawing number 2D3. 1326-163413 shows the details of the end connection. All the copper on the end connection is tinned before assembly. At final assembly the end connections are soft soldered. The outer end of the connections are insulated with a glass tape and epoxyed. An insulated sleeve is installed over the end of the connection and extends approximately five millimeters over the rotor coil insulation.

When the fault occurred, the heat generated by the fault melted the solder which was thrown outward centrifugal1y on the end turns of the stator coils and inside the motor end shields. No damage was done to the stator coils. Extensive arc erosion took place on one of the rotor half coil ends. The copper: evaporated. The fault was phase to phase. The area of the damage is shown circled in red on Siemens drawing number TRA-W 1827/1. At the rotor winding to slip-ring connections, the arc occurred from the bolted joint (rotor winding connection bar to slip-ring bars) to the shaft and slip-ring assembly guard ring which is at the same potential as the shaft. The heat generated by the arc melted the connection solder which was thrown out centrigually to the inside of the outer motor end shield.

\section{Motor Brake Initiation}

The events which immediately preceded the fault namely the tripping of the motor while the power supply was on standby (no pulsing) and the automatic 
initiation of the motor brake were investigated. The annunciators showed:

No flow lubricating oil to bearings $\#_{1}, 2$ and 3 .

Malfunction electrically driven pump 非2.

Shaft driven pump low flow (this does not initiate

motor braking, but initiates starting of elec-

trical1y driven pumps).

Further investigation showed that electrically driven pump 非 did not pump oi1. As set up, pump 非 was the back pump for pump $\# 2$ which was the prime pump. Due to a relay race in the shaft-driven pump failure circuit, the back-up pump always comes in first and shows the prime pump as a malfunction. This also inhibits the prime pump from ever starting. Since pump 非 was called on to supply lubricating oil. because of low flow in the shaft-driven pump and failed to pump oil, the motor brake was initiated. It must be mentioned that the failure of either the shaft-driven pump and the two electrical pumps in supplying oil does not endanger the proper lubrication of the three bearings immediately. Oil rings are installed in each bearing pedestal. These pick-up oil in the pedestal reservoir to lubricate the bearings as the shaft spins in addition to the shaft-driven pump supply. The electric pumps plus lift pumps for each bearing are operated in the normal start-up and shutdown of the motor-generator set, and as already mentioned the electric pumps backup the shaft-driven pump.

\section{Rigging and Repair}

The following is a chronogical report of Mr. D. Davis, Accelerator Department Power Engineer, who was in charge of the logistics in the rigging, transportation, and repair of the motor rotor. Other events that took place are added chronologica11y.

\section{Saturday, August 19, 1972}

Upon arrival at the Siemens Power Supply Building following telephone notification of the motor rotor fault, the slip-ring enclosure had been removed and the motor end shields were being removed. Serious trouble was found in that one or two rotor winding end connections were burned and the rotor to slip-ring connections were severely burned.

It was evident that the rotor had to be removed for repair and Mr. Hansen of Traynor and Hansen Rigging Company was called to request that they be at Brookhaven Nationa1 Laboratory (BNL), Monday, August 21, to look at the rigging 
job and prepare for the work as soon as possible.

Monday, August 21, 1972

A Traynor and Hansen Rigging Company representative arrived in the morning and prepared for rigging to commence the next day, Tuesday, 8/22/72.

The General Electric Service Shop, North Bergen, New Jersey was called to have their representative look at the rotor for repair. Mr. J. Mcclure called and stated that he would be at BNL on Wednesday, 8/23/72 to look at the rotor.

Siemens, New Jersey office, Mr. Max Deterding was called and was informed that we were having the General Electric Service Shop look at the rotor for possible repair by them.

\section{Tuesday, August 22, 1972}

Traynor and Hansen reported and the rigging operation began.

Mr. Max Deterding of Siemens Corp. called and stated that Siemens would like to have the rotor to to Allis-Chalmers in Pittsburg for repair. This is a transformer manufacturing plant. Before we could object to this plant, Siemens said they preferred the Allis-Chalmers, Milwaukee, Wisconsin plant. (Allis-Chalmers has some sort of connection with Siemens, and we expected Siemens to prefer their shop.) We objected on the basis of distance and argued for General Electric since they had done other repairs for BNL, had a shop that is close to BNL, and were capable and equipped to do the work.

\section{Wednesday, August 23, 1972}

Mr. J. McClure of the General Electric Service Shop arrived at BNL and reviewed the repair work. He stated they were familiar with the construction and are prepared to start work as soon as the rotor can be delivered to them.

The rigging to remove the rotor continued.

In the evening, Mr. Klaus Rueschmann of Siemens, Milwaukee arrived at BNL. He carefully inspected the machine and did not commit Siemens to any responsibility. He, however, arranged for a man from Berlin to arrive at BNL early the following week.

\section{Thursday, August 24, 1972}

After consultation with Siemens in Germany, Mr. Deterding withdrew Siemens' objection to the repair of the motor rotor by the General Electric Service Shop of North Bergen, New Jersey, and stated that an engineer from Berlin would report at the New Jersey shop the following week. 
In the morning, Mr. Rueschmann met with several members of the Department staff. He was not at all sure that the failure was due to poor workmanship on the part of Siemens' construction shop in which he expressed complete confidence. A test of the other joints by passing a current of 1000 amperes and looking for warm joints failed to show any other bad joints, but it was agreed that this test was not definitive since the rotor was not spinning and there were no centrifugal forces on the joints. Rueschmann was asked about the wisdom of resoldering a11 of the rotor joints. He felt that the best test would be to destroy several joints by sectioning them. If three undamaged joints proved to be good, he felt that it was safe not to touch the remaining joints.

Friday, August 25, 1972

The rigging of the motor rotor is completed and the Traynor and Hansen truck will deliver the rotor to General Electric on Monday, August 28. General Electric was advised of the delivery.

Monday, August 28, 1972

The rotor was delivered to General Electric Service Shop at approximately 1300 hour.

Tuesday, August 29, 1972

General Electric was called and we were informed that the rotor was being set up on the shop floor and that the winding retaining rings would be removed the following day.

Wednesday, August 30, 1972 (At G.E., N. Bergen, New Jersey)

Mr. J. Cottingham and Mr. D. Davis of BNL, and Mr. G. NageI (Siemens, Berlin, Manager Insulation and Coil Department) and Mr. M. Deterding of Siemens Corp., New Jersey inspected the damage after the retaining rings were removed.

One lower and two upper slot winding coils are definitely damaged. If the lower slot coil can be repaired by splicing new copper to the good remaining portion of the coil, then only twelve upper slot coils must be removed (including the two damaged upper slot coils) to expose the area for repair. If a complete new coil must be used, then twenty-four upper coils must be removed.

The coil insulation at the slip-ring end of the rotor (where the fault occurred) which is under the retaining ring is extremely dirty with carbon 
from the brushes. This is an area that is very difficult to clean and it is evident that the dirt was a major cause of the fault or arc-over between phases.

The insulation and filler at the outboard end of the coil support (see Siemens drawing OD3.1470-163415 coordinate $\mathrm{K} 6$ has blistered paint. When this is removed, small holes show up which may have been caused by tracking. However no other area shows where the tracking originated. Mr. Nagel, the Siemens engineer, insists that the holes are typical in the poured epoxy which is used in this area.

The details of the work were discussed and agreed upon.

The slip-ring diameters were measured to see if the ring wear is over the Siemens recommended minimum. The following measurements were recorded: W ring - 657.35 millimeters, V ring - $655.44 \mathrm{~mm} \mathrm{Mp}$ (neutra1) - $658.57 \mathrm{~mm}$, U ring - $657.80 \mathrm{~mm}$. Siemens instruction book shows $654 \mathrm{~mm}$ minimum diameter. The $V$ ring diameter is thus very sma11, only $0.72 \mathrm{~mm}$ of material allowable for wear. The ring has considerable material remaining and Siemens was requested to review the minimum allowable ring diameter.

The epoxy glass insulation which BNL installed at the slip-rings has carbon from the brushes adhering to the surface. This was cleaned very well by G.E. using a solvent "MID-SOLV" which is a perchlorethylene.

\section{Friday, September 1, 1972}

Twelve upper coils were removed quite easily with only one copper bar being damaged (bent). There are two bars to each coil. The mica insulation was nicked and damaged on al1 of the twenty-four bars during removal; they will need to be reinsulated if they are to be used as good spares.

The damaged lower coil can be repaired in place thus requiring that only twelve upper coils be removed. The coil bar bent during removal will be used to provide the copper for the repair of the damaged lower coil.

The repair will be done by brazing using fifteen percent (15\%) silver. 
The coil to be repaired was cut here and new copper was Edge of rotor steel

brazed with staggered joints as shown. The brazed joints were then ground to bar size. The repair work on the coil was completed on this day and it is an excellent job.

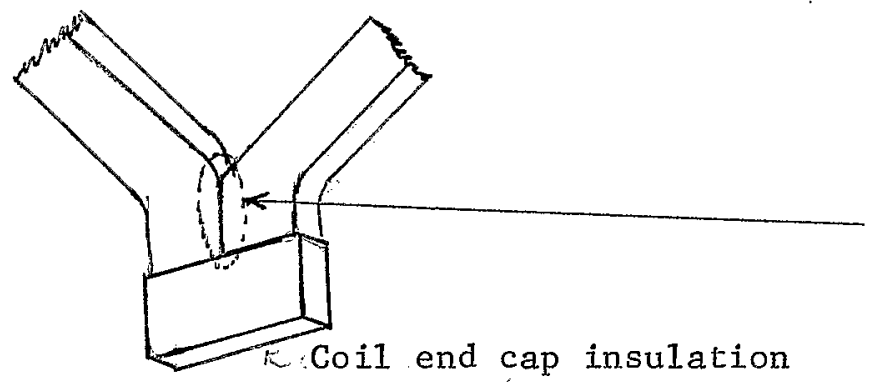

The coil end connection has a small space between coils in this area which allows dirt to collect and shorten the creepage path to conductors'.

under the end cap insulation. The major portion of the fault was in this area. A11 end cap insulation will have this space filled with an epoxy and the complete area will be insulated with glass tape and epoxy.

Siemens "epoxy mica paint" will be used over the glass tape/epoxy insulation between the slip rings.

The connector bolts at the connection between the slip-ring bars and the rotor winding connecting strap were too long and thus too close to the shaft. The bolts will be turned around to get more clearance to the shaft and the shaft in this area will be insulated with glass tape and epoxy.

The rotor was steam and detergent cleaned Friday night and was put in an oven for the three-day weekend to dry.

Wednesday, September 6, 1972

The twelve upper coils were installed in the slots and wedges.: The spare coils and new wedges were used. 


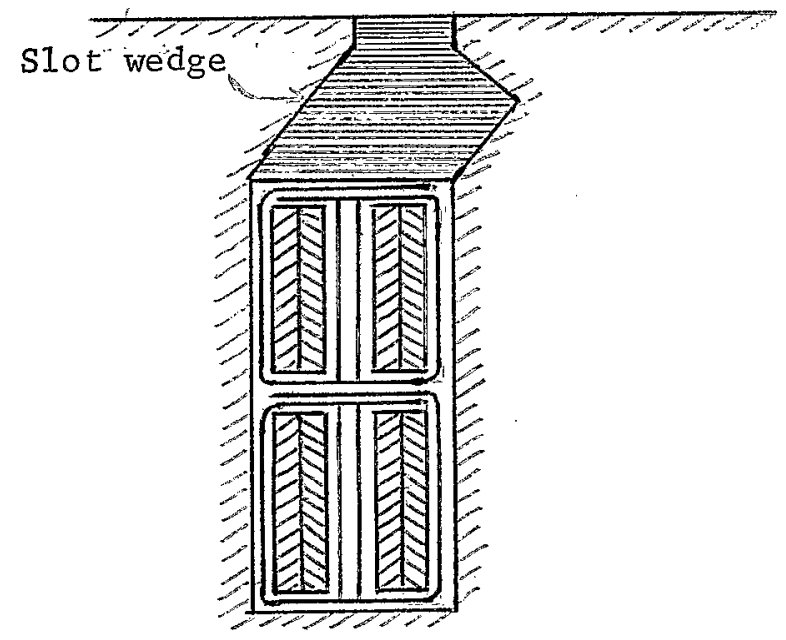

The old slot liner insulation was folded over at the top of the bottom coil and a new $U$ shaped Iiner insulation was insta1led with the upper coil.

A11 coil end cap insulators were filled with epoxy in addition to the space between coils and each connectors. They were then glass taped and epoxyed. The epoxy used to fill the end caps is Astro Chemical Co., Schenectady, New York, "Barco Bond" two part mix equal of each. The glass tape is held in place with Scotch Grip 非1300L adhesive.

The insulation at the end of the coil support member was cleaned in preparation for the installation of a fiberglass epoxy cover to be done Thursday, September 7. Please refer to Siemens drawing number oD3.1470163415 coordinates $\mathrm{K} 6$. The area shown in red denotes the added fiberglass epoxy cover.

Friday, September 8, 1972

The rotor was hi-pot tested after completion of the coil installation and connections, but before connection to slip-rings. The results were 10,000 volts applied 5 microamperes leakage or 2000 megohms.

The rotor was moved to the lathe and set up for the installation of the epoxy glass insulation band over the coil ends. The glass tape used is G.E. \#16830 and "Permafi1" polyester resin G.E. 非3405. Four thousand five hundred (4500) yards of $3 / 4$ in. wide tape was used at each end of the rotor. The tape was applied under 500 pounds tension. After application, the tape and polyester was cured for two days at one hundred ten (110) degrees Celsius.

Monday, September 11,1972

The rotor was back in the lathe and the tape over the coil ends was turned to dimension for shrink fit of steel retaining bands. 
Wednesday, September 13, 1972

The rotor was out of the lathe and a hi-pot test was made before the steel retaining bands were put on. With the winding connected to the sliprings the results were 10,000 volts applied, 150 microamperes leakage or 66.7 megohms.

The rotor connecting bars from the winding to the slip-rings are to be insulated Thursday, September 14, and the complete job is to be painted with insulating varnish.

Friday, September 15, 1972

The rotor balance was completed with $0.6 \mathrm{mils}$ final reading. Balance weights were added -7 lbs. at the slip-ring end and 6 1bs. at the coupling end.

The rotor insulation resistance was checked and was 300 megohms with a 1000 volt megger.

The rotor resistance was measured with a Biddle Company "Ducter" and is as follows:

$\begin{array}{llc}M p-U & 0.006 \text { ohms } & \text { @ approximately } 20^{\circ} \mathrm{C} \\ \text { Mp-V } & 0.006 " & n \\ \mathrm{Mp}-\mathrm{W} & 0.006 " & " \\ \mathrm{U}-\mathrm{V} & 0.0115 " & " \\ \mathrm{U}-\mathrm{W} & 0.0115 " & " \\ \mathrm{~V}-\mathrm{W} & 0.0115 " & "\end{array}$

The rotor was painted and will dry over the weekend. It will be ready for pick-up by Traynor and Hansen on Monday or Tuesday.

G.E. Service Shop was given the "go-ahead" to reinsulate the twenty-three rotor winding bars that were removed and replaced during the repair. These bars will be insulated with epoxy flake mica tape molded to the slot dimensions. The tape is G.E. $\#_{177809}$. G.E. Service Shop will retain the crate for the spare coils, pack these coil bars with the remaining original spares and ship the complete crate to BNL. This will give BNL spare rotor coils in the same quantity as originally purchased.

Wednesday, September 20, 1972

The motor rotor was delivered at BNL by Traynor and Hansen. 
Thursday, September 21, 1972

The rigging of the motor rotor was started.

Friday, September 22, 1972

The motor rotor was in the stator bore ready for coupling to the generator. The weight of the rotor is off the stator.

Saturday, September 23, 1972

The motor rotor rigging was completed ready for the alignment of the motorgenerator set.

Week of September 25, 1972

The motor-generator set alignment was completely checked and corrected where required.

\section{Investigation of Lubricating 0i1 System Failure}

During the repair of the motor rotor, the causes for the failure of the motor-generator set lubricating oil system were investigated. As mentioned earlier the shaft-driven pump and the back-up electrically driven pumps failed to deliver a sufficient quantity of oil.

The pumps were disassembled and thoroughly examined for signs of wear or component failures and none could be found. Each pump suction Iine has a foot valve (check valve) installed at the lower end of the pipe line near the bottom of the oil tank. See Siemens drawing number 2D8.6701-167338 coordinate B5. These check valves were disassembled. It was found that the check mechanism seal had deteriorated. See Figs. 10 and 11. The material used to seal at the valve seat (not shown) was some type of rubber which had become spongy, distorted, and eroded in the case of pump 非 check valve where the flow was not impeded when tested. In the case of pump 非 1 the sea 1 materia1 was so bloated as to impede the proper operation of the valve and thereby to restrict the normal flow of oil.

Since pump 非 and 非 are we11 down into the tank, and therefore selfpriming, the suction line check valves were completely removed. The check valve at the lower end of the shaft-driven pump suction line exhibited the same problem as the others in that the seal material was spongy and bloated to the point that it seriously restricted the normal flow. The seal material is very evidently not compatible with the lubricating oil. This oil is Mobil DTE medium grade oil without any inhibitors. Since this check valve must hold 
fifteen feet of oil to prevent the loss of charge of oil for the shaft-driven pump, it was repaired using Buna-N synthetic rubber material to replace the defective seal material.

The relay race problem with the electrically driven oil pump control circuits was corrected.

\section{Generator Rotor Servicing}

During the time when the motor rotor was in the General Electric Service Shop, the generator rotor was rigged out of its stator onto the floor of the motor-generator set room. The Siemens Instruction and Maintenance Manual recommends yearly inspection of the rotors of both the motor and generator. The CERN laboratory of Geneva, Switzerland who also owns a Siemens power supply with an identical generator and a six megawatt motor turning at $1000 \mathrm{rpm}$ have pulled out their rotors two times since the power supply went into operation. At both times the generator rotor had to be serviced. The field coil brace retaining bolts had become loose and needed retightening.

Inspection of the AGS generator rotor showed the same condition. See Fig. 12, generator rotor, and Siemens drawing number 1D1.1384-156656, field coil brace. In the photograph, the field coil braces (Iight color) are shown between the poles. There are six braces between each of the six poles. As shown on the field coil brace drawing, one bolt retains the brace. The bolt head is locked by a lock plate to prevent it from turning. In turn the brace compresses insulation blocks onto the field coils.

During normal pulse duty, the generator delivers energy during the acceleration and flat top part of the magnet pulse cycle. Then the power supply inverts and the generator is operated as a motor to recover a good part of the stored energy in the magnet. During the changeover from one mode of operation to the other, the generator torque direction changes.

During normal operation, the poles expand thermally due to the field pole current and elastically due to the high centrifugal force. These compress the insulation blocks at the field coil braces. With continuous operation, the insulation blocks become thinner requiring the tightening of the field coil brace retaining bolts periodically. Since these retaining bolts are not easily accessible while the rotor is inside the stator, the rotor must be pulled out to accomplish the tightening.

The field coil brace were tightened down and the retaining bolts were 
torqued to 150 foot-pounds. The generator rotor was rigged back into the stator and completed Wednesday, September 20.

\section{Motor-Generator Set Air Cooling}

The motor-generator set air cooling is a closed system with air to water heat exchangers--two for the motor and four for the generator--installed on chimneys in the motor-generator set pits. The pits are separated from each other by a sealed door, and the motor and generator are each separately enclosed by bolted on end covers.

The air is drawn in axially by centrifugal action of the motor rotor, by fans and centrigual action of the generator rotor. The air is blown through the stator cores down the chimney, through the air to water heat exchangers and up again to the axis of the machines.

Both machines have slip-rings adjacent to the one of the end covers. The covers are sealed to the shaft with bakelite covers with about ten thousandths of an inch clearance. The generator slip-rings are in the open, whereas the motor slip-rings are enclosed and force ventilated. The air pressure in the slip-ring enclosure is three and a half inches of water.

The air pressure at the axis of each machine is slightly negative and the brush dust due to brush wear is forced into the inside of the covers via the shaft sea1 clearance because of the differential pressure.

Blowers were installed, one for each machine, to pressurize the closed air systems. The blower outlet in each case is orificed to determine the static pressure which is adjusted to 5 to $5 \frac{1}{2}$ in. of water for the motor and $1 \frac{1}{2}$ in. of water for the generator. With a pressure inside the machines higher than immediately outside the machines, brush dust will not enter into the inside.

\section{Liquid Rheostat Repairs and Improvements}

The motor-generator set motor is started and braked by means of a liquid rheostat connected to the motor rotor. The electrolyte is a one percent sodium carbonate solution in water. The 1iquid rheostat assembly consists of two open-ended tanks coupled together to form a single tank. One part contains the fixed and movable electrodes and the other part contains three heat exchangers to cool the electrolyte. The two part tank and the heat exchangers are made of steel. 
Since the start of operation of the power supply a year and a half ago, one of the three heat exchangers developed a leak in one of its cooling tubes. Investigation showed that the inside of the cooling tubes had become corroded and partially plugged up with a hard substance. The cooling water used is treated with hexametaphosphate.

The three heat exchangers were retubed with 90-10 cupro nickel tubes. The liquid rheostat tank inside surfaces were painted with three coats of Pittsburg Aquapon epoxy paint over one coat of primer. The last coat was cured for seven days before filling the tank with the electrolyte.

Distr: Department Administration AGS Division Staff 


\section{Figure Captions}

Fig. 1 Siemens Motor Generator Set.

Fig. 2 Rotor Winding.

Fig. 3 Rotor Winding.

Fig. 4 Rotor Winding

Fig. 5 Rotor Winding.

Fig. 6 Rotor Winding.

Fig. 7 Slip-Ring Connection.

Fig. 8 S1ip-Ring Connection.

Fig. 9 Slip-Ring Connection.

Fig. 10 Foot Valves.

Fig. 11 Foot Valves.

Fig. 12 Generator Rotor.

\section{Drawings}

Dwg. No. 2D3.1326-163413

$$
\begin{aligned}
& \text { Rotor Winding Cap } \\
& \text { Rotor Winding Diagram } \\
& \text { Rotor Winding Plate 非 } \\
& \text { Rotor Winding Plate 非 } \\
& \text { Rotor Winding } \\
& \text { Winding Support } \\
& \text { Oil Piping System } \\
& \text { Field Coil Brace }
\end{aligned}
$$$$
\text { TRA-W 1827/1 }
$$$$
\text { OD3.1470-163415 }
$$$$
\text { 1D3.1470-163416 }
$$$$
\text { OD3.1471-163417 }
$$$$
\text { 1D3.1848-163423 }
$$$$
\text { 2D8.6701-167338 }
$$$$
\text { 1D1.1384-156656 }
$$

\footnotetext{
*Colored prints and drawings referred to above are available on request.
} 


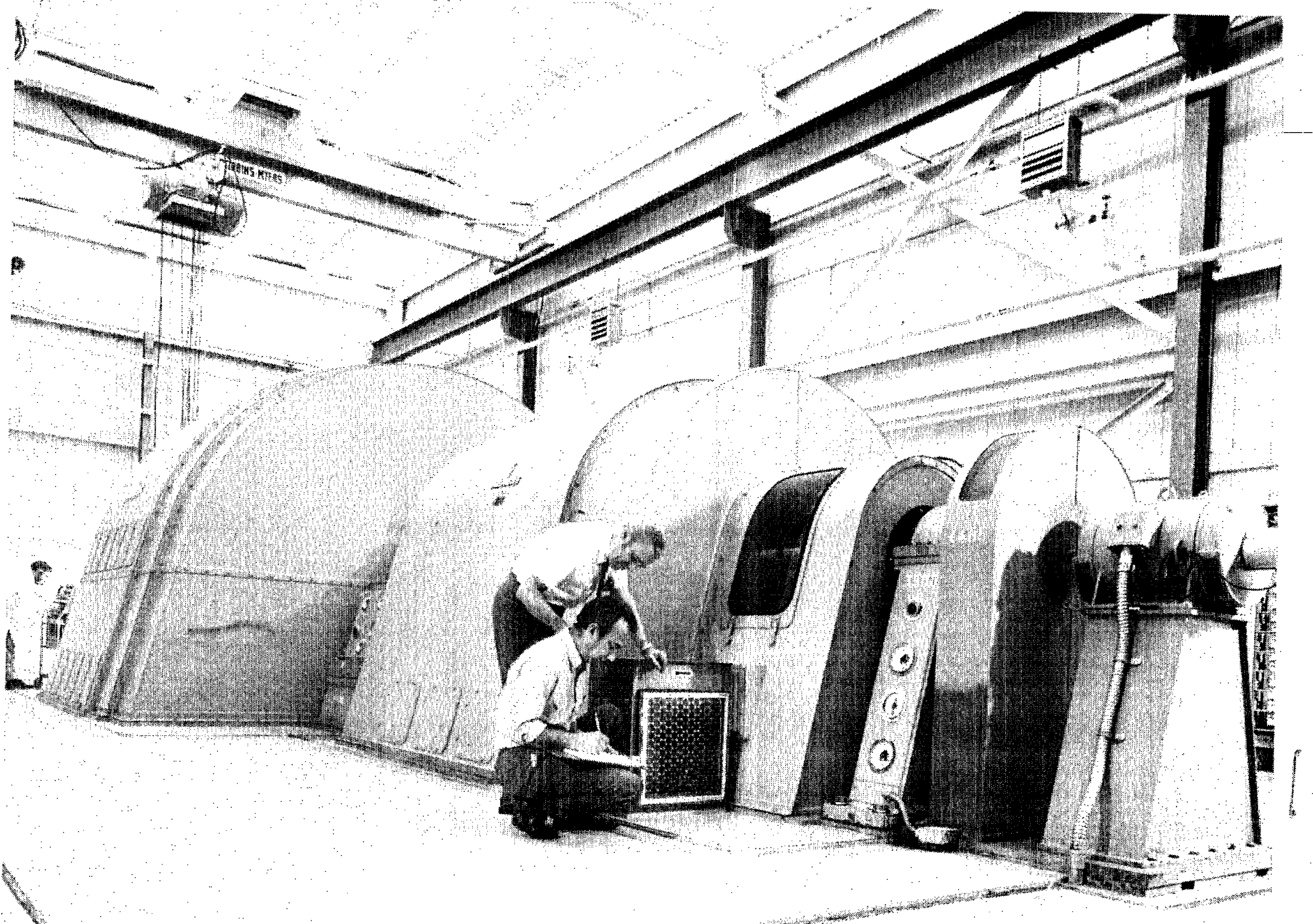


W

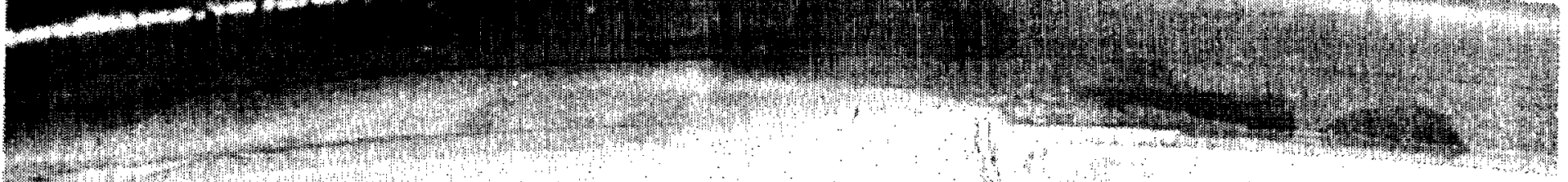

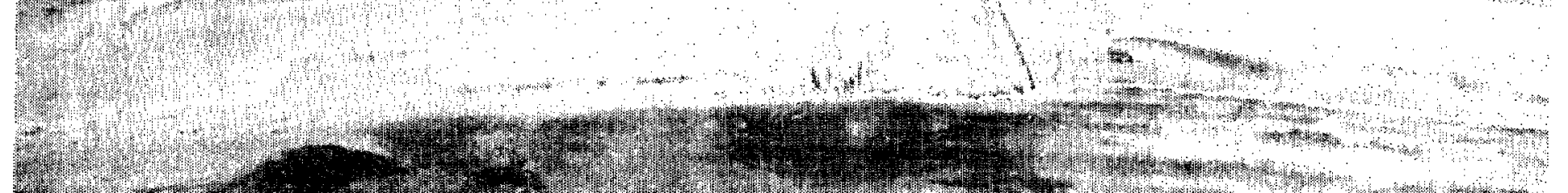

W

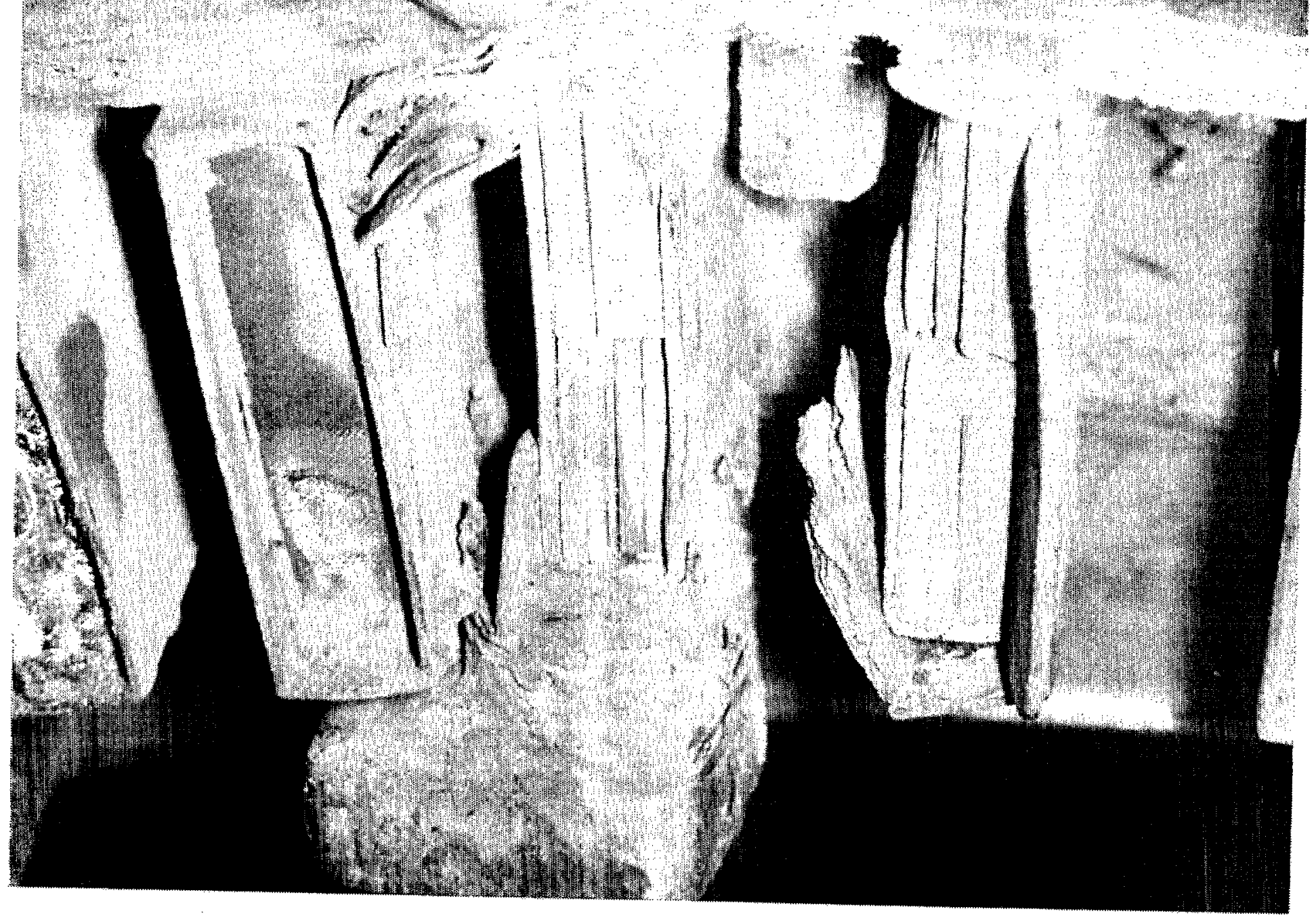

Fis. 3 


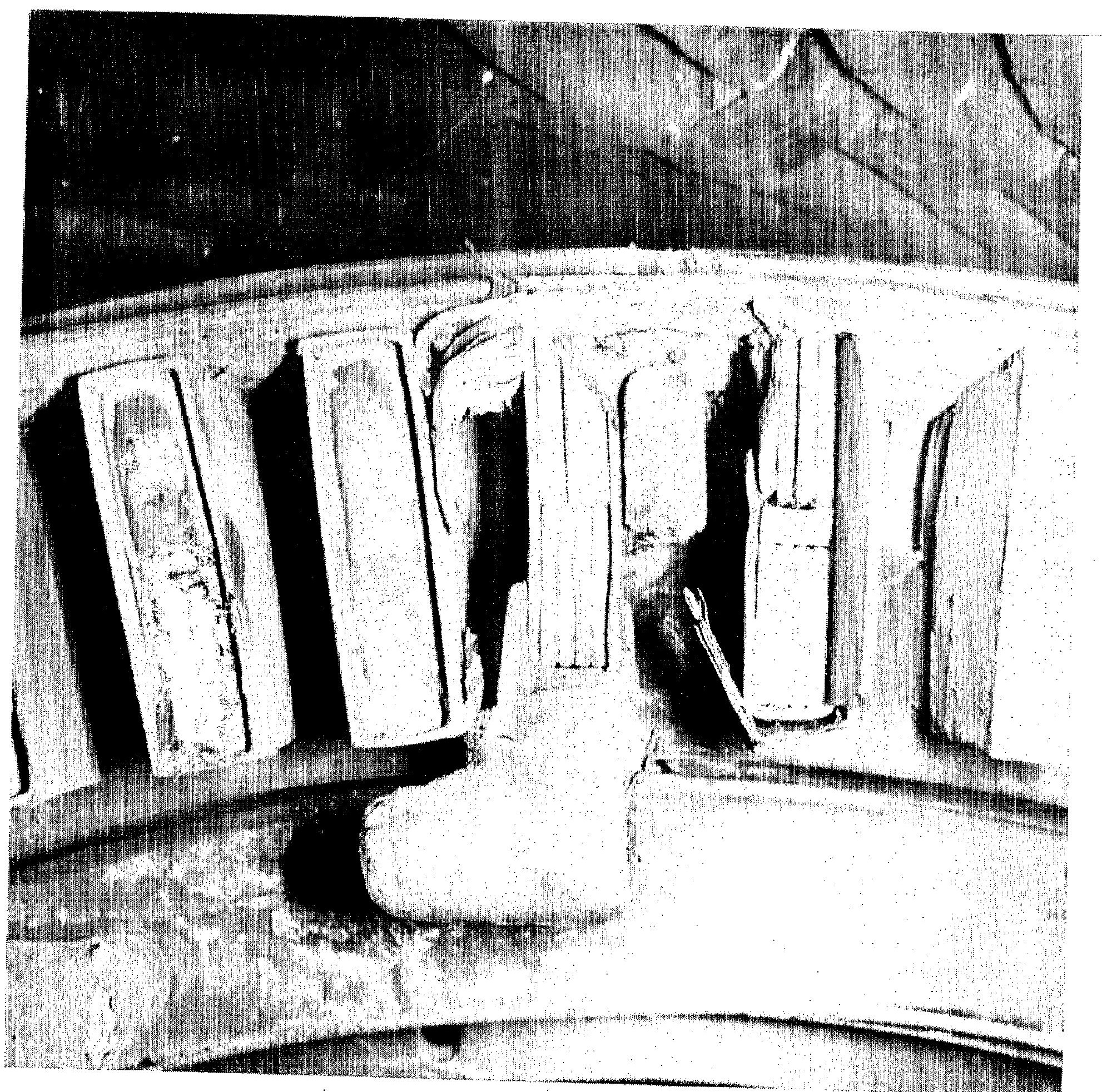




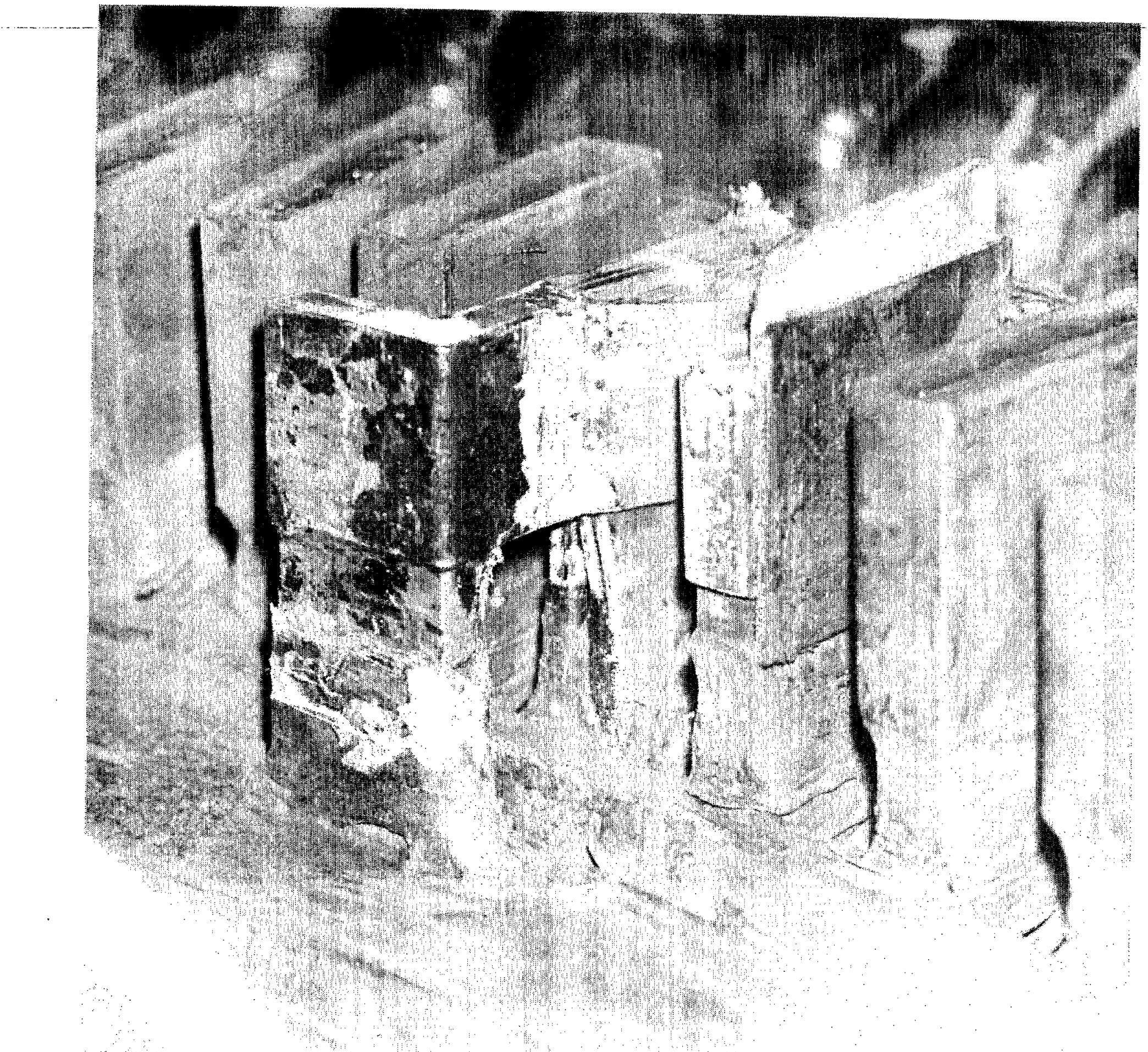




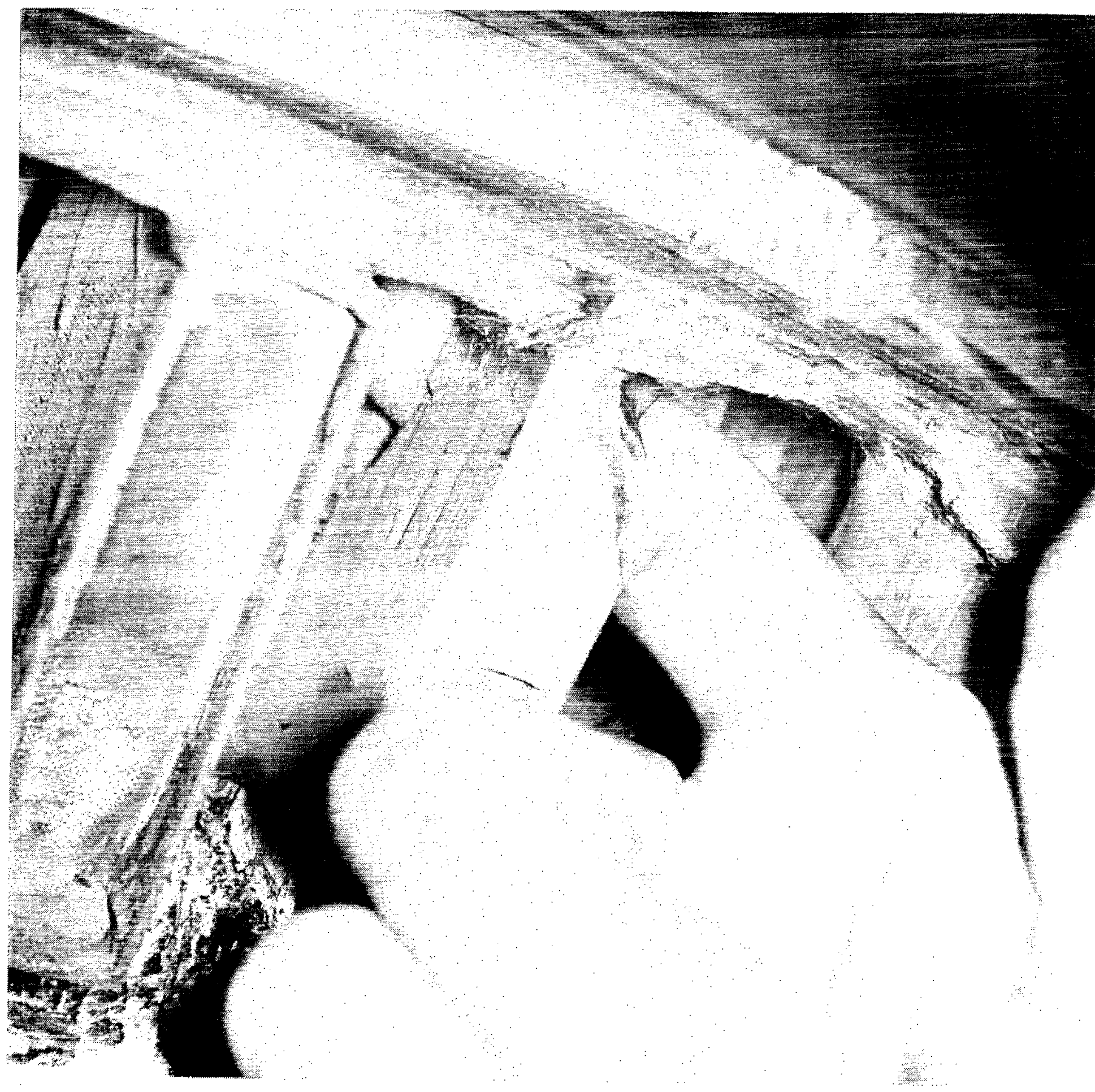

Tig * 6 


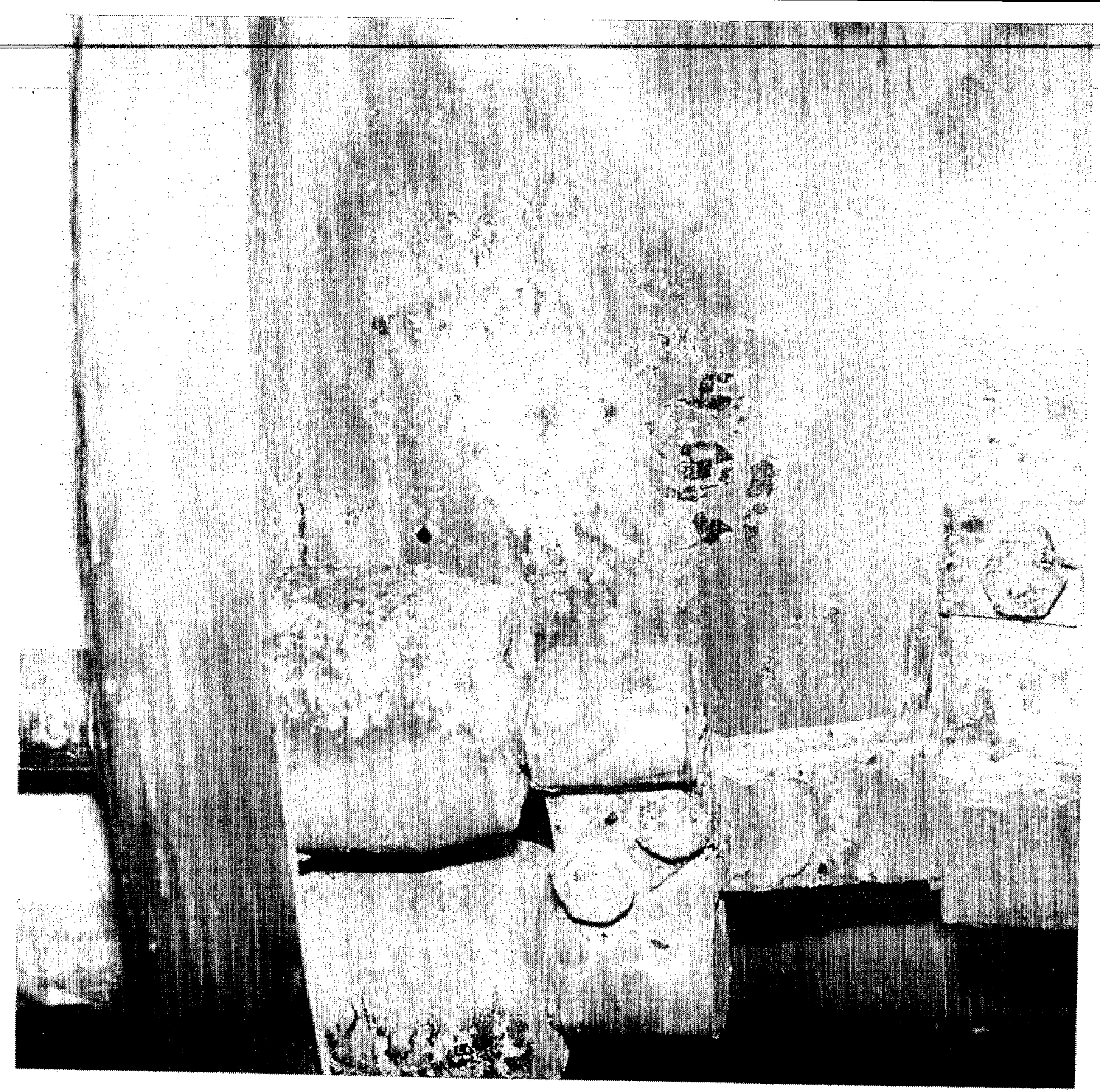

Eig. 


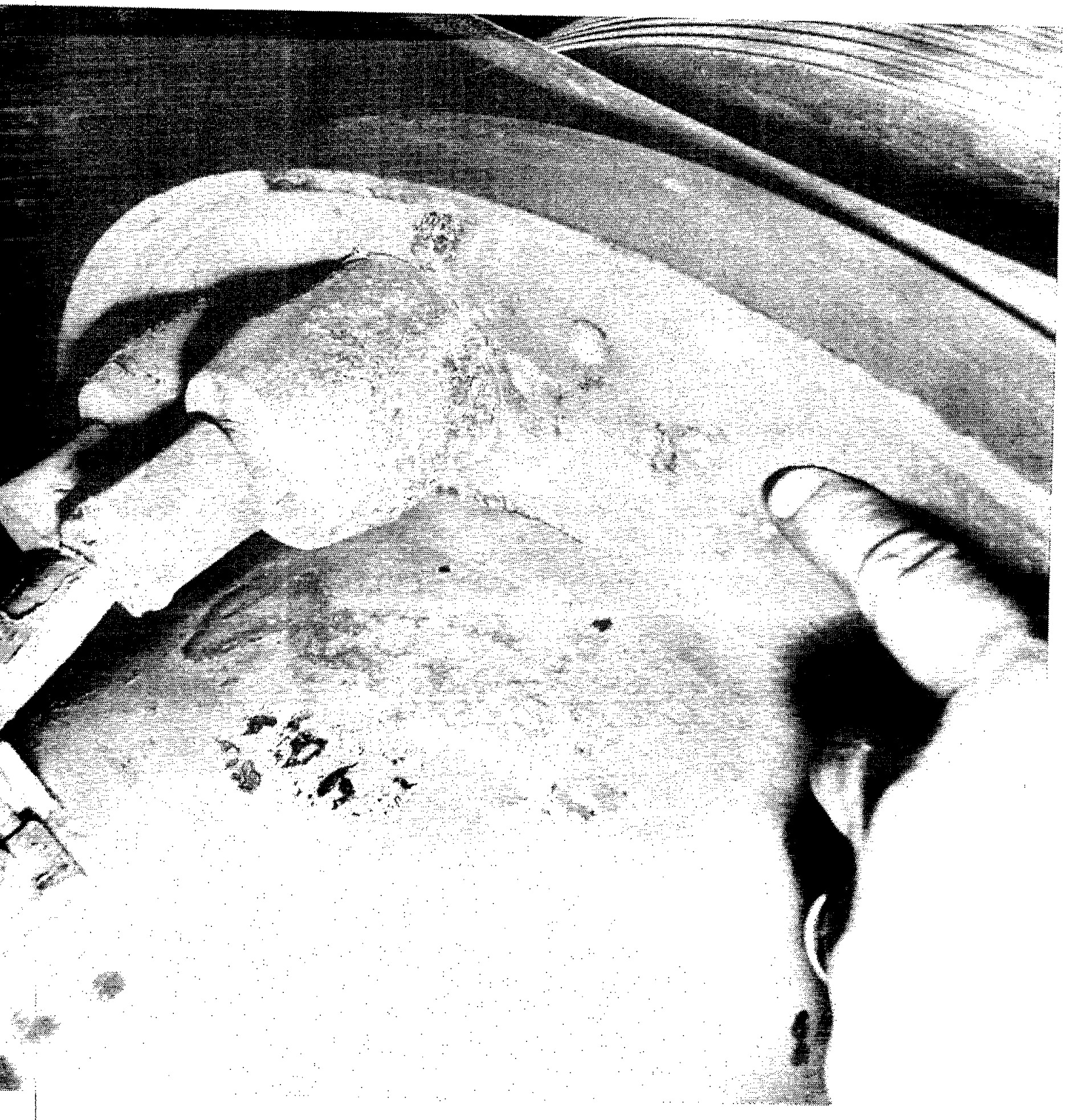

Fis.g 

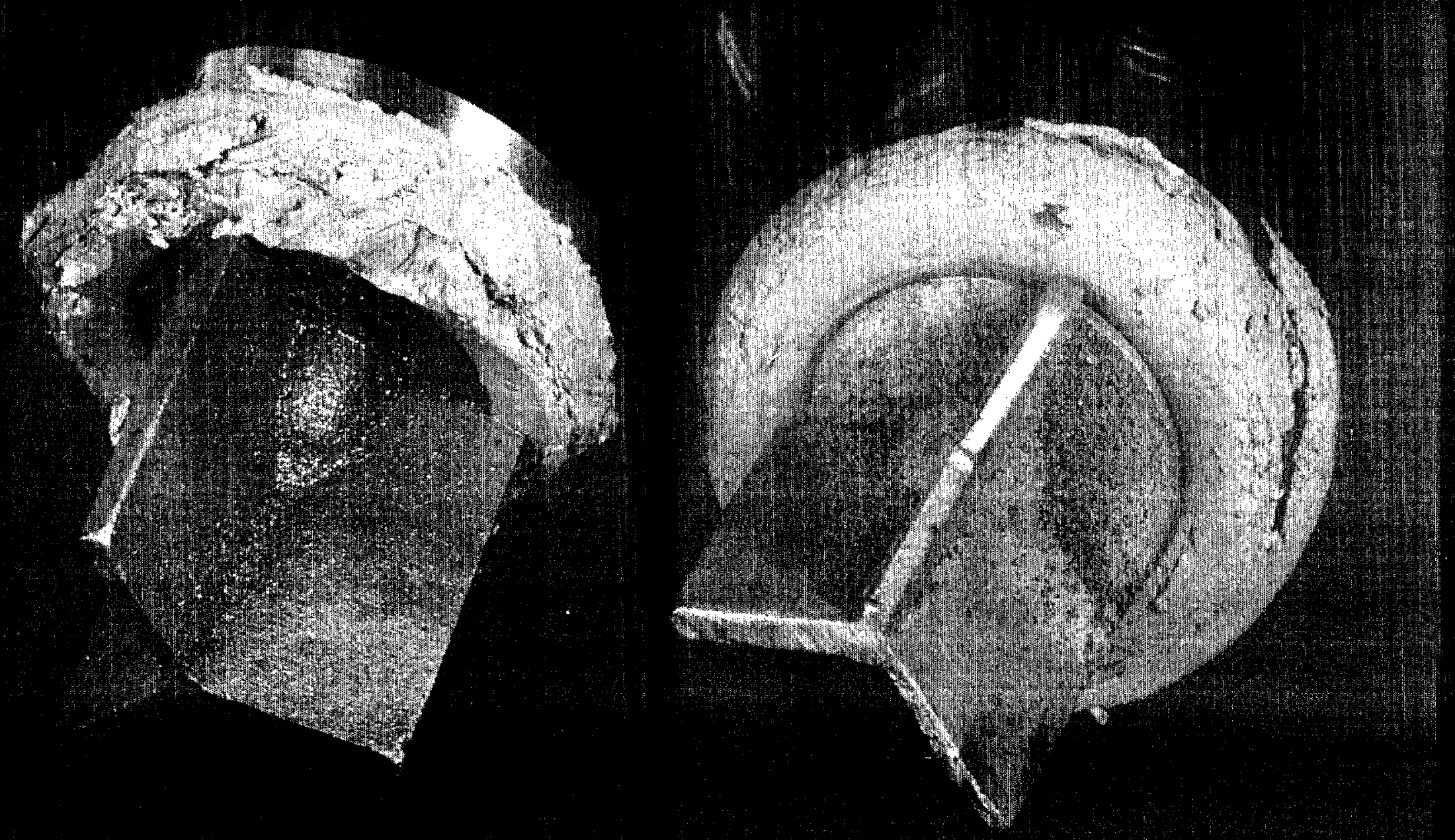


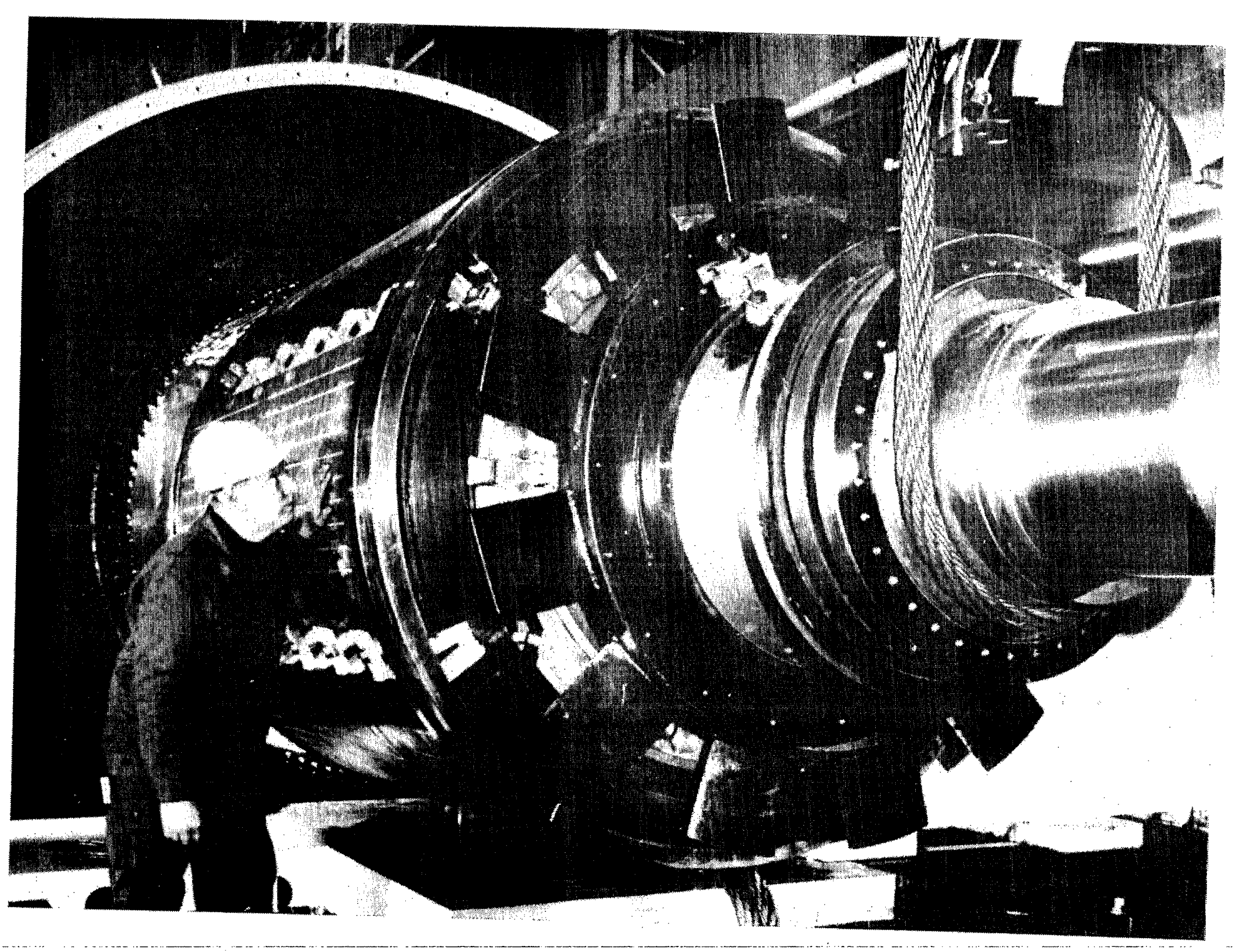

